\title{
ACOMPAÑAR EN TIEMPOS DE PANDEMIA Algunas propuestas desde la teología pastoral
}

\author{
Accompany in Times of Pandemic
}

JOHN EDWARD TRUJILLO RÍOS

Universidad Católica de Oriente, Colombia

\begin{tabular}{ll}
\hline KEY WORDS & ABSTRACT \\
\cline { 2 - 3 } $\begin{array}{l}\text { COVID-19 } \\
\text { Loneliness }\end{array}$ & $\begin{array}{l}\text { Since the beginning of the pandemic caused by SARS-CoV-2, the measures } \\
\text { Accompaniment }\end{array}$ \\
Grace & distancing and confinement, these guidelines that have been a great \\
Prayer & challenge for spiritual accompaniment. Fear and anxiety have appeared \\
Pastoral & strongly due to this global event, which calls for a new form of help. \\
Theology & Under these circumstances, the question arises: how to carry out a \\
& ministry of support when precisely we must lock ourselves up to avoid \\
& more infections? In this work, from pastoral theology, it's intended to \\
& elaborate some proposals to answer this question that involves creativity \\
and adaptation.
\end{tabular}

\section{PALABRAS CLAVE}

COVID-19

Soledad

Acompañamiento

Gracia

Oración

Pastoral

Teología

\section{RESUMEN}

Desde el inicio de la pandemia ocasionada por el SARS-CoV-2, las medidas para prevenir este nuevo coronavirus han consistido principalmente en el distanciamiento social y el confinamiento. Directrices que han supuesto un gran reto para el acompañamiento espiritual. El miedo y la ansiedad han aparecido fuertemente debido este suceso de carácter global, que reclama de una nueva forma de ayuda. Bajo estas circunstancias, surge la pregunta: ¿cómo realizar un ministerio de apoyo cuando precisamente debemos encerrarnos para evitar más contagios? Desde la teología pastoral deseo elaborar unas propuestas para dar respuesta a este interrogante que supone de creatividad y adaptación. 


\section{Introducción}

$\mathrm{E}$ 11 de marzo de 2020 la organización mundial de la salud (OMS) declaró estado de pandemia debido a la enfermedad ocasionada por el COVID-19. Un nuevo virus que tomó por sorpresa a todos los ciudadanos de nuestro planeta, y que hasta el día de hoy (24 de noviembre de 2020) sigue provocando desastres a nivel general. La ciencia ha presentado una esperanza por medio de algunas vacunas, que hasta el momento presentan un alto porcentaje de protección ante el nuevo coronavirus. De lo que se tiene seguridad hasta el presente, es que se puede disminuir drásticamente el contagio con medidas provisorias, tales como el uso de mascarillas, el distanciamiento social y el confinamiento.

Estas últimas disposiciones han significado un gran reto para la salud mental de muchas personas que han tenido que sufrir casos de ansiedad, estrés, nervios, falta de sueño, entre otros síntomas a causa de no poder salir de casa (Valero, 2020, pp. 64-65) mientras la facturas y las deudas van en aumento. Son muchos los afectados por esta pandemia. No solo los que se contagian por el nuevo coronavirus, sino los que pierden su trabajo y los que sufren desde casa por soledad. Desde estas realidades vale la pena preguntarse cómo hacer posible un acompañamiento que responda de alguna manera a las inquietudes, miedos y preocupaciones que sufren millones de personas.

Mientras escribo estas líneas, hice parte del círculo que apoyó de diferentes maneras a un amigo que se encontraba enfermo de COVID-19 en Navarra (España). Familiares y amigos nos hicimos presentes por medio de llamadas, videollamadas o mensajes de WhatsApp para saber cómo se encontraba y verificar su evolución. Pero no solo personas allegadas colaboraron en este propósito. También sus compañeros de estudio que viven junto a él, un colegio que alberga a estudiantes de diferentes naciones, hicieron un gran esfuerzo para guardar la cuarentena preventiva, ayudando de esta manera para que no se expandiera más el virus. Vale la pena también hacer notar el trabajo del personal de cocina y aseo que estuvieron tan pendientes de sus comidas y limpieza de ropa. Se logró con esta acción conjunta no solo su sanación, sino evitar la expansión del virus.

Desde esta experiencia surge así la pregunta: ¿sólo se puede hablar de apoyo cuando se da éste de manera próxima, personal y afectivo-corporal con alguien que padece por algún motivo? En caso de que se pueda hablar de un nuevo modo de ayuda iel acompañamiento incluye también las tecnologías, la distancia y el apoyo al enfermo desde su puerta? ¿qué elementos de juicio y qué propuestas se puede elaborar desde la teología pastoral?

Para responder a los anteriores cuestionamientos se desarrollará el tema mediante el método teológico pastoral ver-juzgaractuar que vincula la realidad con elementos de contraste para generar propuestas desde la teología. Desde el primer nivel, que comprende el ver, se trata de contemplar la realidad de una pandemia con sus consecuencias como son el miedo, la falsa información, la falta de trabajo y la vivencia de soledad. Desde estos elementos, se trata de iluminar (juzgar) desde Cristo estas situaciones que, piden de un fundamento seguro cuando ni la ciencia ni la economía logran responder de manera rápida y efectiva. Por último, se trata de proponer (actuar) algunas acciones que comprenda la fuerza de Dios como elemento inicial, para hacer presente su Reino mediante diferentes propuestas.

\section{La aparición de un virus que nos confina}

Cuando la OMS declaraba la presencia de un virus que se propagaba por contacto social, el miedo se ha apoderado de muchas personas. Debido a que el COVID-19 se transmite principalmente por contacto con los enfermos y por medio de las gotitas que se producen al hablar o toser (OMS, 2020), ha provocado que se expanda rápidamente, debido a una sociedad globalizada. Situación que ha exigido restricción en las actividades sociales, del trabajo presencial, de cambiar todo un modo de vida ordinario.

Aunque están claras las medidas, a la hora de llevarlas a la práctica se nota mucha dificultad. La falta de un salario estable provoca que una gran masa de la población se vea obligada a salir, aun en medio de confinamientos estrictos. Situación que ha llevado a países 
latinoamericanos a enfrentar una grave situación de contagio. En casas y hospitales se encuentran enfermos guardando largos períodos de confinamiento junto con personal de la salud y familiares que pueden contraer este virus.

Bajo este panorama deseo situar el acompañamiento. Se trata de plantear un apoyo para el enfermo que no puede recibir visitas, la persona desempleada debido al confinamiento o aquél que llora porque no ha podido estar cerca de su familiar que ha fallecido. Significa ello responder a la ansiedad e incertidumbre que ha generado la pandemia. Temor que inicia por no tener aun ni vacunas legítimamente validadas por la OMS, ni un medicamento que contrarreste sus efectos en el cuerpo. Contexto que provoca mucho tipo de información, saturando a la población con diferentes opiniones, teorías y posverdades que, si no se saben discernir, terminan confundiendo por completo.

\subsection{El COVID-19 como noticia viral}

Ya sea en noticieros, documentales, en prensa o radio, la información acerca de la pandemia se ha vuelto un escenario constante que amenaza con nuestra salud mental. Algunos han decidido leer solo lo que les interesa, bien sea por internet o prensa, y evitar estar muchas horas del día viendo análisis de contagio, muertes, y todo lo que alrededor del nuevo coronavirus se pueda argumentar. Esta actitud no se debería interpretar directamente como un escape de la realidad. La verdad es que, ante una indagación tan desbordada, se hace necesario buscar una armonía y silencio interior que permita desahogar la saturación de un tema.

Las opiniones con respecto al virus se dan de todo tipo, y si el televidente no tiene suficiente discernimiento para discernir lo más importante de lo menos, puede quedar más confundido de lo que estaba al inicio. Algunos presidentes, entre ellos Jair Bolsonaro, han calificado al COVID-19 como "gripita" (BBC, 2020). Para otras personas esta situación es el inicio del fin del mundo, y por tanto es necesario esperar lo peor. Extremos que producen muchas dudas, temores y ansiedades. El negacionismo científico que ha hecho su aparición hace algunas décadas (McIntyre, 2018, p. 43), ha vuelto al escenario ante un ambiente tan caótico y necesitado de respuestas contundentes para enfrentar la pandemia. Mientras algunas personas niegan la presencia del virus, para otros es un desastre sin precedentes que puede acabar con la raza humana. Ante esta confusión cabe la pregunta ¿qué hacer con tanta información difusa?

Gallegos y otros, recomiendan primero que todo no negar la situación por la que se está pasando como tampoco generar un pánico extremo que produzca que las estanterías de los supermercados queden vaciadas, perjudicando con ello a la población en general. Incluso con respecto a los niños, recomiendan que no se les niegue ningún dato, teniendo en cuenta no exponerlos a muchas noticias que les pueda ocasionar algún trastorno (2020, pp. 5-10).

A nivel de la información recomiendan solo estar atentos a los organismos oficiales de salud, evitando la de dudosa procedencia, teniendo presente la científica por encima de la opinión (Gallegos, 2020, p. 22). Cuando no se pueden manejar la enorme cantidad de resultados que brota tanto de internet, se produce un ambiente de estrés y temor continuo. Si a esto se le agrega una dosis permanente de pesimismo y tragedia por parte de los medios, el sistema nervioso se recarga fácilmente.

\subsection{Una situación de crisis a diferentes niveles}

La Organización Internacional del Trabajo (OIT) para América Latina y el Caribe da cuenta de una situación económica precaria debido al nuevo coronavirus. Su director, Vinícius Pinheiro, declaró acerca de las dificultades por las que atraviesan los pueblos debido a los confinamientos:

Enfrentamos un desafío sin precedentes, el de reconstruir los mercados laborales de la región, lo cual implica abordar las fallas estructurales que han agudizado la pandemia, tales como la baja productividad, el nivel elevado de informalidad, y la desigualdad de los ingresos y de oportunidades de trabajo decente (OIT, 2020).

En este informe Pinheiro habla de 34 millones de trabajadores que perdieron su empleo (OIT, 2020). Aunque en la cantidad total se encuentran algunos que perdieron su trabajo de manera temporal, se establece según el informe, un 
panorama desolador. Por otra parte, personas que viven de un trabajo informal o que tienen deudas, no pueden darse el lujo de quedarse en sus casas para guardar cuarentena. Son muchos los que se han visto obligados a salir para trata de rebuscar el mínimo para vivir. Lamentablemente los más pobres son los más expuestos al COVID-19.

La relación falta de oportunidades - riesgo de contagio, se ha convertido en proporcional. Aunque si bien, los gobiernos han buscado salidas para mitigar las consecuencias de la falta de empleo, estas ayudas llegan a un pequeño porcentaje. La crisis mundial expone la situación de los más vulnerables, que son los que más sufren en cualquier calamidad. Como bien dice Pedro Trigo: "La pandemia ha puesto al descubierto lo que la falsa normalidad encubría: que la mayoría de la humanidad no cuenta" (Trigo, 2020, pp. 15-17).

Sin embargo, vale aclarar que no todo es malo. La pandemia también ha dejado ver la gran capacidad que han tenido las personas para sobreponerse a las adversidades. En este sentido son muchos que desde lo poco que tienen han sabido compartir: "ante todo, la solidaridad horizontal de los pobres entre sí. Sin ella se hubieran muerto muchísimos" (Trigo 2020, 16). Un tiempo incierto como éste, ha puesto de relieve grandes héroes a nivel científico. Desde el personal médico que arriesga sus vidas para salvar otras e investigadores que con gran anhelo y esfuerzo buscan una vacuna para detener este virus.

A nivel humano, no se puede dejar de anotar la gran valentía de muchos sacerdotes, sicólogos, terapeutas, cuidadores que han ayudado a paliar y sobrellevar las situaciones de crisis, tristeza, depresión, entre otros muchos factores, que necesitan de una mano amiga. Son los acompañantes en medio de la pandemia. Un ambiente que confronta, y ayuda a discernir lo fundamental de lo accesorio: "la pandemia nos ha bajado de un porrazo a nuestro lugar común de seres mortales, imperfectos y necesitados de trascendencia" (Moreno, 2020, p. 29).

Desde esta experiencia ya se puede responder al primer cuestionamiento planteado. Sí se puede hablar de un acompañamiento en este tiempo. El testimonio de muchos familiares, amigos, profesionales de la salud entre muchos otros, dan cuenta de lo que es saber estar presente, aunque muchas veces no sea de manera física. Ismael Moreno habla incluso de prepararnos para un "acompañamiento de resistencia" en el que es necesario ofrecer ayuda para momentos de largas dificultades, de hastío y desesperanza, para mostrar la luz de Dios en medio de esas oscuridades (2020, p. 30).

\section{Ayudar a la luz de Cristo}

Al confirmar el acompañamiento que pueden prestar tantas personas en tiempos del COVID-19, ahora se trata de buscar los elementos de juicio para hablar de un ministerio que permita dar respuesta a las inquietudes de las personas. Para ello se presenta a Cristo como luz y esperanza en medio de situaciones de ansiedad y temor. Si bien, para muchos la ciencia lo era todo, después de estos sucesos, esta afirmación puede entrar en crisis. A pesar de los adelantos tecnológicos con los que se cuenta hoy en día, la vacuna sigue en pruebas. Unas generan mayor esperanza, sobre todo porque se encuentran en fase 3. Sin embargo, se debe contar con paciencia porque una decisión apresurada podría tener un efecto contrario. Saldría peor el remedio que la enfermedad.

En esta experiencia de dudas, desconocimiento y gran incertidumbre, el ser humano reclama algo en qué o quién confiar. Desde esta visión, el papa Benedicto XVI afirmaba: "no es la ciencia la que redime al hombre. El hombre es redimido por el amor...el ser humano necesita un amor incondicionado... si existe este amor absoluto con su certeza absoluta, entonces -solo entonces- el hombre es redimido" (2007, 261). Se va descubriendo así que, no se trata de un aprendizaje solo intelectual, sino de una experiencia vital, de un encuentro con una Persona que puede guiar en medio del vacío existencial.

En el camino de búsqueda, se puede presentar la pregunta por un Dios que permite el dolor. Sin embargo, desde la opción por Cristo, se da un encuentro no con un dios impasible que se burla

\footnotetext{
${ }^{1}$ De ahora en adelante los documentos del Magisterio de la Iglesia no les anoto la p. de página, según el criterio APA, pues al tomarlos directamente de la página oficial del Vaticano, anoto solo su numeral correspondiente.
} 
del hombre o dictamina juicios desde su cielo. Se trata del Hijo que entrega su vida para la salvación del mundo. Afirma al respecto B. Forte: "es el Dios con nosotros, que sufre con nuestro dolor porque nos ama, que lo permite porque nos deja libres, que precisamente su Hijo crucificado nos ayuda a llevar la Cruz como él la llevó" (Forte, 2020, pp. 40-41).

\subsection{Ampliación del término "acompañar"}

Visto el ministerio de asistencia, como un estar físico y literalmente cercano con la persona, desde la lógica que se viene desarrollando, parece que queda incompleto. Desde un primer nivel, la definición que ofrece el diccionario de la real academia española expresa acompañar como: "estar o ir en compañía de otra u otras personas" (RAE, 2001, p. 33). Para Domínguez consiste, desde este punto de vista en: "caminar junto a otro estando ahí, hacerse presente a través del encuentro, pero sin invasión, creando confianza y seguridad" $(2017,12)$. En este itinerario, se trata entonces de una definición de cercanía, comprendiendo el abrazo y la capacidad de poder ver a los ojos directamente.

Se podría decir entonces que la definición estricta de acompañamiento apunta a un apoyo de mano amiga desde la atención físico personal. Antonio Ávila expone una definición de "acompañamiento pastoral" refiriéndose a una tarea que nace en las acciones realizadas por Jesús buen pastor. Desde este enfoque se trata de la preocupación por el prójimo: "especialmente aquel que necesita de cualquier manera de nuestra presencia fraterna, tanto por motivos de crecimiento personal y espiritual como a causa de problemas materiales, morales, psicológicos, situaciones de exclusión, angustia y miedo" (2018, p. 13).

En la experiencia de muchas personas, la cercanía no ha significado automáticamente sentirse amado o entendido. Sucede en el caso de los que sufren soledad, aunque estén con su pareja, en familia o en medio de un estadio de fútbol (cuando se podía). Mientras en otros casos, personas que están físicamente solas, como puede ser el caso de solteros, estudiantes de intercambio, soldados, enfermos, entre muchos otros, se sienten amadas $y$ comprendidas, pues cuentan con un apoyo incondicional de familiares y amigos.

Desde esta premisa deseo impulsar un acompañamiento que vincule tanto los medios tecnológicos como humanos y espirituales con el fin de saber vencer las dificultades que trae consigo una pandemia. En este horizonte se trata de empatizar y compadecerse con aquél que sufre, bien sea por la falta de empleo, la enfermedad o por una ansiedad que no le deja dormir. Ello supone saber escuchar a través del WhatsApp, detrás de la puerta o a dos metros de distancia. Significa reconocer la experiencia de la enfermedad, como un momento para llevar a cabo un adecuado recurso humanitario:

Todo enfermo tiene necesidad no solo de ser escuchado, sino de comprender que el propio interlocutor sabe que significa sentirse solo, abandonado, angustiado frente a la perspectiva de muerte, al dolor de la carne, al sufrimiento que surge cuando la mirada de la sociedad mide su valor en términos de calidad de vida. (Congregación para la doctrina de la fe, 2020, II).

Se trata de un servicio que vincula más la atención en la experiencia significativa, aunque no se pueda contar con la ayuda física cercana. Sabe así el acompañante que supone mostrar el camino y no en convertirse en protagonista de un proceso. Facultad que se obra por medio de una llamada, la ayuda de la limpieza, o a través de una oración. Con ello no se apela a una renuncia física cuando se pueda realizar, pero los tiempos actuales exigen de creatividad para expresar un abrazo, aunque sea de manera virtual.

De todas maneras, sin importar las acciones que se ejecuten, lo importante es saber direccionar. Si el apoyo conduce a centrar la atención solo en el ayudante o en la persona afectada para que caiga en un narcisismo agotador, perdería fácilmente el rumbo todo ese esfuerzo. Ya lo decía bien el papa Francisco: "el acompañamiento sería contraproducente si se convirtiera en una especie de terapia que fomente el encierro de las personas en su inmanencia y deje de ser una peregrinación con Cristo hacia el Padre" (2013, 170). Mas bien, consiste en conducir hacia Aquél que puede sanar, que comprende el dolor, porque Él mismo ha padecido hasta derramar su última gota de sangre. 


\section{2. "Una palabra tuya bastará para sanarle" (Mt 8,8)}

El evangelista Mateo describe a través de este texto un ejemplo de fe no en un judío, un sacerdote, fariseo, o alguien cercano a Jesús. Lo expresa a través de un centurión que lo reconoce como aquél que sana, que tiene un poder tan grande que no hace falta que esté personalmente al lado del enfermo, pues su palabra vence el confinamiento, la enfermedad y los temores: "pero el centurión le replicó: -Señor, no soy digno de que entres bajo mi techo. Basta que pronuncies una palabra y mi criado quedará sano" (Mt 8, 8).

En este versículo se encuentra una gran inspiración para un acompañamiento en tiempos de COVID-19. Consiste primero reconocer en la persona de Cristo la salud del cuerpo y del alma. Un Dios que llega a nuestras realidades y se compadece del enfermo, del que ha perdido su negocio, del que sufre a causa de la pérdida del amigo. El nuevo Cafarnaúm es nuestro territorio, el lugar donde nos encontramos, bien sea confinados o en nueva normalidad. La parálisis del enfermo (Mt 8,6) se puede simbolizar en la incapacidad de movernos y de obrar, aun con toda la tecnología que el mundo tiene a disposición. Es una experiencia de impaciencia e impotencia que nos acorrala, invitando a buscar esperanza en la medicina, la investigación y en Cristo (siempre como opción) que vence el dolor y toda extraña enfermedad.

En las problemáticas que trae el coronavirus, Dios pide a cada acompañante la fe del centurión. Así como ese soldado sabe que tiene "un superior" (Mt 8,9), nosotros tenemos un Diosamigo que prevalece sobre nuestras fuerzas y expectativas, para saber esperar con confianza. Desde la experiencia de los conocidos que nos ofrecen ayuda, la fe nos invita a disponer nuestras dudas y temores en Cristo. Él es la persona que nos puede sanar y tranquilizar: "ve y que suceda como has creído" (Mt 8,13).

El acompañamiento reconoce la fuerza de Dios que llega para sanar las heridas: "en aquel instante su criado quedó sano" (Mt 8,13). Implica reconocer la presencia siempre nueva de Jesucristo por medio de su palabra, que ilumina las oscuridades de la mente y produce la paz en medio de la impaciencia. Los temores que afloran con el confinamiento y el estrés pueden ser vencidos: "pues la Palabra de Dios es viva y eficaz y más cortante de espada de dos filos" (Heb 4,12).

La lógica del que ayuda se basa entonces en un saber desaparecer para que Él se haga presente. Se trata de actualizar la praxis de Juan el Bautista, en la que Cristo "debe crecer y yo disminuir" (Jn 3,30). Cuando un virus ha llegado a nuestra realidad, impactando diferentes dimensiones de la vida ordinaria, se hace necesaria la virtud de la humildad que invita a reconocer un fundamento que va más allá de nuestras seguridades humanas. Ha llegado la hora de disminuir el ego y confiar profundamente en Dios.

Es la oportunidad para vencer falsos mesianismos que el mundo ha propuesto. Invita a la reelaboración del sistema económico actual para proyectar una administración solidaria que tenga en cuenta a los más vulnerables. Si bien el virus no hace diferencia de clases, lo que mejor se han podido proteger son aquellos que pueden quedarse en la seguridad del hogar sin la preocupación de cómo pagar alquiler o la comida. Juan Bautista no se ha dejado llevar por los espejismos de mesías. Reconoce en Cristo el verdadero fundamento de toda vida. Se identifica como el mensajero, pero desde la humildad del creyente: "detrás de mí viene uno con más autoridad que yo, y yo no tengo derecho para soltarle la correa de las sandalias" (Mc 1,7).

\section{Propuestas de acompañamiento desde la teología pastoral}

Después de haber abordado elementos de contraste para un acompañamiento en tiempos de COVD-19, el siguiente paso consiste en proponer algunos puntos de acción que permitan dar respuesta a los desafíos que produce el confinamiento, la soledad y otras dificultades del presente. Desde este horizonte, se propone la primacía de la gracia en la tarea exigente y profunda de orar por el enfermo. En un segundo momento, desde la concepción de acompañamiento en sentido amplio, se invita a un compartir con el que sufre. Esto lleva a un apoyo en lo social para intentar que los gobiernos y las administraciones guíen los 
recursos y fuerzas hacia el bien común. Por último, se impulsa una ayuda que ofrezca luz de esperanza hacia aquella persona que ha perdido a un familiar por causa del nuevo coronavirus o de otra enfermedad.

\subsection{Solidarizarse desde la oración}

En la seguridad de que la obra es de Dios, la plegaria cobra una gran importancia para los momentos en que sentimos desdicha, temores y dudas de frente a lo que vivimos. Desde este aspecto, la primacía de la gracia se convierte en un elemento fundamental para el acompañamiento 2 . El encuentro con Jesús es la experiencia vital de abandono en medio de la resistencia, de encontrar consuelo para el vacío que produce una situación inédita con sus desastres: "esta es la confianza que tenemos al acercarnos a Dios: que, si pedimos conforme a su voluntad, él nos oye" (1 Jn 5,14).

El camino de la fe no significa un itinerario fuera de dudas, temores o sufrimientos. Implica, más bien, direccionar aquello que nos afecta como seres humanos, asumiendo los miedos como respuesta normal de nuestro cuerpo ante los desafíos que nos sobrepasan. No se trata de sentimientos que debamos esconder por el miedo a la crítica social. Son estados que nos defienden de amenazas ${ }^{3}$ y nos vinculan de un modo nuevo con Dios, desde la experiencia de finitud y fragilidad: "en mi angustia invoqué al Señor, clamé a mi Dios, y él me escuchó" (Sal 18,6).

Es el proceso que me vincula hacia la esperanza, aun cuando esté solo, sin con quién compartir por un buen tiempo de un café o un abrazo: "cuando ya nadie me escucha, Dios

\footnotetext{
2 El Papa Juan Pablo II en su carta apostólica Novo Millenio Ineunte, afirma la necesidad de una programación pastoral que de importancia a la oración personal y comunitaria para manifestar la acción de Dios en todas las acciones eclesiales. Actuando de esta manera, se respeta el principio de la primacía de Dios, sobre la tentación de pensar que los resultados dependen solo del ser humano. (Cf. Juan Pablo II, 2001, 38).

${ }^{3}$ Gallegos y otros afirman al respecto: "El miedo no sólo es una respuesta natural frente a una situación de incertidumbre y desconcierto como la que se ha instalado de manera generalizada, sino además contiene una ventaja adaptativa que es preciso utilizar a nuestro favor, pues nos hace estar alerta y nos permite orientar la toma de decisiones, favoreciendo conductas más responsables con nosotros/as y con los demás" (Gallegos, 2020, p. 6).
}

todavía me escucha. Cuando ya no puedo hablar con ninguno, ni invocar a nadie, siempre puedo hablar con Dios" (Benedicto XVI, 2007, 32). Consiste en aquella confianza del orante que confía al Padre sus necesidades, desde lo secreto de la habitación (Mt 6,6). En el caos que pueda vivir, allí se hace presente la gracia como armonía que va poniendo sentido a todo ese embrollo. No lo hace de manera inmediata. Más bien va actuando de manera suave, sin que me dé cuenta, pero haciéndose efectiva. Como bien apunta Zolezzi: "siempre es posible realizar una experiencia de gracia en un contexto de desgracia" (2018, p. 379).

Se debe tener en cuenta que la oración no me deja hablando solo. Para muchos podría tratarse de una actividad de meditación que lleva solo a una disposición interior de relajación y bienestar. Sin negar lo anterior, la oración va mucho más allá. No es una búsqueda del propio equilibrio para quedarse encerrado en un narcicismo agotador. La capacidad de abrirme a la gracia me dispone cada vez más a la fraternidad con los hermanos (Benedicto XVI, $2007,33)$. La pandemia nos ha puesto contra las cuerdas, y nos ha hecho ver nuestras fragilidades y la necesidad de la solidaridad. Nos pone en evidencia la falta de un fundamento, de una salvación integral que sobrepasa el bienestar material, y que invita una opción trascendental (Congregación para la doctrina de la fe, 2018, 6).

\subsection{Hacerse presente con el vulnerable}

Desde la definición de acompañamiento como estar cerca de alguien de manera física, se pasa a un saber hacerse presente de manera significativa. Una relación que se establece desde Dios a través de la oración, utilizando los recursos tecnológicos o los protocolos establecidos para llegar al necesitado. Una llamada telefónica a alguien que se siente solo, preguntar por su salud a través de un familiar, e inclusive compartir un buen rato con la distancia adecuada, son ejemplos de ello. Lo importante es hacer notar a la persona que aun cuenta y es importante, que puede ser atendida, aunque se encuentre encerrada.

Es fácil sentirse relegado cuando ya no se produce en el actual estilo de vida que llevamos. Vivimos bajo la presión laboral y social de estar 
realizando alguna actividad para ser comprendidos como personas. Se nos va olvidando que el trabajo está hecho para edificar al hombre y no al contrario. Desde la concepción de Jesús, implica que no todo puede ser iniciativa humana, sino que es necesario abandonarse a la voluntad del Padre: "fíjense en las aves del cielo: no siembran, ni cosechan, ni almacenan en graneros; sin embargo, el Padre celestial las alimenta. ¿No valen ustedes mucho más que ellas?" (Mt 6,26). Vivimos en una sociedad híperrotulada, donde se le da un trato especial al doctor, magíster, excelentísimo, venerabilísimo, y todos los ísimos existentes, pero poca aceptación al pobre, excluido, enfermo, anciano, $\mathrm{y}$ todas aquellos que no pueden laborar, ni demostrar títulos o cuenta bancaria.

Necesitamos renovar nuestras relaciones con la dinámica de la gracia que reconoce en el otro a un hermano, a otro Cristo: "si uno te obliga a caminar mil pasos, haz con él dos mil. Da a quien te pide y al que te solicite dinero prestado no lo esquives" (Mt 5,43). Es lamentable reconocer que algunas de nuestras amistades parecen más relaciones contractuales que verdaderos espacios de regocijo y encuentro. Desde la primacía de la gracia, se reconoce el gran valor de la vida humana, sin importar la posición social o la capacidad que tiene una persona para ayudarme con dinero o algún ascenso en el trabajo.

Estar presente con el excluido no solo es un momento para ofrecer un mejor acompañamiento. Es la gran oportunidad de manifestar la misericordia de Dios que es gratuita, pues nadie se la merece, ni nadie tiene derecho a arrogarse la salvación (Ef 2, 9-10). De alguna manera todos somos necesitados, y en ese plano, la ayuda que se ofrece es la expresión actual del Reino de Dios que va en búsqueda de la oveja perdida (Mt 18,10) y del que se encuentra herido en el camino (Lc 10,30).

Desde la opción preferencial por los pobres, se hace un anuncio de Cristo como salvador, pues desde la promoción humana se anuncia sin distinción alguna la acción de Dios misericordioso. No se trata de una exclusión de las personas, sino de un enfoque contextual en el que los escándalos por corrupción aquejan los pueblos latinoamericanos, acentuando la desigualdad social y la pobreza extrema. Se hace necesario y urgente construir una mejor convivencia, en una sociedad justa y libre (CELAM, 1979, p. 1153-1154).

\subsection{Acompañar en lo social}

La ayuda espiritual tiene una gran conexión con la dimensión humanitaria. Desde el principio de la gracia, la acción de Dios siempre impulsa a la apertura hacia los demás, y en este campo se hace crucial apoyar, vigilar y motivar una justicia social que busque el favorecimiento de los más pobres, en las políticas que se manejan desde los pueblos y naciones, para que las líneas de acción busquen el mejoramiento de las políticas que favorezcan el bien común.

Lamentablemente se ha opacado a lo largo de los años la relación entre gracia - espiritualidadrealidad social. La relación gracia espiritualidad ha sido presentada muchas veces desconectada de toda experiencia comunitaria, para referirse solo de una manera estática a la relación del Creador con el hombre, desde un plano abstracto. Se olvida que la acción de Dios tiene su influjo en la historia cotidiana, en el tiempo y el espacio, con sus efectos sociales y prácticos (Zolezzi, 2018, p. 377). De este modo podría pasar que la reflexión teológica y pastoral resulte tan extraña a los desafíos actuales, que se hable por separado del plano teológico y del real.

Sin embargo, lo anterior se trata más bien de una mirada superficial de la fe. Ella no excluye ni la realidad, ni los problemas urgentes que apremian de un discernimiento y un actuar para el favorecimiento de las personas, sobre todo de los más vulnerables: "muéstrame tu fe sin obras, y yo te mostraré por las obras mi fe" (Stg 2,18). Ya el papa Pablo VI en su exhortación apostólica post-sinodal Evangelii Nuntiandi, hacía referencia a la necesaria adhesión del Reino de Dios con la realidad vital y comunitaria de los pueblos. Una vinculación que no se puede quedar en lo ideal, sino que se debe hacer visible en las comunidades $(1975,23)$.

El sacerdote jesuita Ismael Moreno, ferviente defensor de los derechos humanos, en este sentido argumenta el apoyo a los pueblos necesitados. Para ello es necesario acompañar a las personas en sus demandas y protestas, para que los gobiernos respondan con la asistencia sanitaria y alimentaria. Desde la cercanía con las 
personas, se puede promover la solidaridad a través de huertos familiares e iniciativas urbanas que vinculen varias ONG, la Iglesia $y$ voluntariados para que desde lo poco que se tiene, se pueda compartir con los que viven en la miseria (Moreno 2020, p. 29-31).

Otra forma de ayuda es a través de la denuncia. Se evoca así la imagen del guardián de los hermanos del profeta Ezequiel: "-Hijo de Adán, te he puesto de centinela de la casa de Israel. Cuando escuches una palabra de mi boca, les darás la alarma de mi parte" (Ez 3,17). Esta forma de cooperación incluye poner en evidencia a todos aquellos que tratan de desviar los recursos para sus intereses personales. Realizando estos trabajos de solidaridad y profecía desde lo local, se va expandiendo un obrar universal fraterno que ayude a testimoniar el amor de Dios a través de las obras (Moreno 2020, p. 31).

\subsection{Simbolizar el dolor con ritos de despedida}

Una de las situaciones difíciles a enfrentar debido al confinamiento ha sido el hecho no haber despedido a conocidos $y$ amigos contagiados con COVID-19 que murieron durante el tratamiento hospitalario. También han sido muchos los casos de personas enfermas de otras causas que han fallecido, y que no han podido tener un sepelio normal. En muchos casos, solo algunos del seno familiar pudieron estar en el cementerio, para ver como sepultaban a quien no pudieron despedir. Vale la pena reconocer que fueron muchos sacerdotes, pastores $y$ representantes de diferentes confesiones quienes estuvieron también presentes para celebrar un breve ritual de despedida.

Diversas investigaciones han comprobado lo necesario del ritual funerario para lograr un duelo sano y bien vivido ${ }^{4}$. Desde el punto de vista

\footnotetext{
${ }^{4}$ Desde el proyecto de tesis de Laura Yoffe "La influencia de las creencias prácticas religiosas/espirituales, en el afrontamiento de la pérdida -por muerte- de un ser querido" ha comprobado lo importante y necesario de llevar a cabo el debido ritual de sepelio, desde las culturas y expresiones propias de cada pueblo: "A partir de entrevistas con adultos entre 30 - 70 años de diferentes religiones, se corroboraron efectos positivos de la participación en ritos funerarios, colectivos y privados... les ayudó a atravesar los
}

antropológico, generan una mejor alianza entre familia y amigos además de ayudar a controlar emociones extremas: "las dinámicas del ritual tienen funciones interpersonales que ayudan a reestablecer los vínculos sociales y a disminuir el sentimiento de soledad" (Yoffe, 2014, p. 147). La celebración vincula la tristeza de la ausencia y la esperanza de un mundo futuro. Estos aspectos se ponen de relevancia: "en objetos, palabras y gestos con un sentido simbólico a fin de reafirmar el deseo de vivir y de trascender a la muerte con la creencia de una vida más allá de lo terrenal" (Torres, 2006, p. 111).

Debido a que no se ha podido llevar a cabo el rito funeral, a causa del confinamiento, se pueden realizar diferentes acciones simbólicas que ayudan a elaborar el duelo. Para algunas personas ayuda escribir una carta dirigida a Dios, expresando los sentimientos de nostalgia y tristeza por la partida del familiar. Para otros, realizar una oración familiar de frente a la foto del difunto, ofrendando un cirio, es una opción de rito exequial en casa que invita a abandonarse, desde la oración, a la providencia de Dios. Otras familias, en el rezo del santo rosario y la imagen de la Jesús en la Cruz, logran expresar su llanto, que libera de las cargas emocionales.

Una celebración litúrgica para tener en cuenta en la nueva normalidad es llevar a cabo los ritos funerarios, sin el cuerpo presente. Se trata de una opción que han tomado muchas personas, logrando posponer un proceso importante que ayuda para vivir adecuadamente el duelo. La oración eclesial permite fundar la fe desde la experiencia de situación límite en la que reluce la confianza del discípulo de Cristo en una situación reciente que requiere de nuevas formas para sobrellevar las cargas.

\section{Conclusión}

Desde la declaración del estado de pandemia, el mundo ha entrado en situación de crisis. El nuevo coronavirus ha provocado un ingente gasto de recursos para buscar una vacuna, sobrellevar el confinamiento, atender a los

momentos dolorosos previos y posteriores a la pérdida y a realizar la separación definitiva del familiar fallecido" (Yoffe, 2014, p. 151). 
enfermos, disponer nuevos lugares para atención y cuidado, entre otros muchos retos. Una situación que requiere de gran discernimiento de los líderes políticos para lidiar con el binomio salud-economía de la mejor manera posible.

La vivencia de los temores e incertidumbres reclaman de un fundamento seguro. La búsqueda conduce la atención hacia alguien que sepa dar razón, esperanza y sentido en medio de estas circunstancias que desgastan y generan mucha impotencia. La persona de Jesús resulta así iluminadora para dar armonía en medio del caos. La necesidad de lo incondicional en medio de la gran finitud $y$ fragilidad es una necesidad imperante.

El acompañante encuentra en Jesucristo un modelo que lo invita a reconocer sin miedo sus temores y limitaciones. Desde esta capacidad, se puede atender de mejor manera al enfermo, pues desde la misericordia se dispone fácilmente la vida y el corazón. Un proceso que permite direccionar hacia Dios, verdadero protagonista de la sanación y la salvación. Desde el relato del Centurión y la praxis de Juan el Bautista, se reconoce la fe incondicional y la humildad, como dos elementos fuertes para saber dar luz en medio de la oscuridad.

Entre las propuestas desde la teología pastoral se encuentran el solidarizarse desde la oración para entregar en las manos de Dios las dudas, los temores y sufrimientos. Hacerse presente con el vulnerable es una oportunidad importante para manifestar su misericordia que es gratuita, sin interés ni condición. Un acompañamiento que invita a apoyar en lo social y convertirse en centinela de los hermanos, para verificar que las ayudas se entreguen como corresponden.

En el manejo del duelo, se ofrecieron algunas sugerencias que promueven su vivencia adecuada, a través de rituales que invitan a confiar en Dios la persona fallecida. Experiencias importantes para simbolizar lo que no se puede explicar fácilmente. Acciones que favorecen una mejor comprensión del dolor, que se muestra como misterio, y que requiere de Dios para saber dar sentido a lo profundo. Esta crisis es la oportunidad de saber encontrar en Jesucristo el amor incondicional y fundamental para nuestros miedos. Es la oportunidad para reconocerlo como nuestro salvador. 


\section{Referencias}

Ávila, A. (2018). Acompañamiento pastoral. Madrid: PPC.

BBC. (2020). Coronavirus: Jair Bolsonaro critica las medidas de confinamiento y compara el COVID-19 con un "resfriadito". (25 de marzo). https://www.bbc.com/mundo/noticias-america-latina-52032551

Benedicto XVI. (2007). Spe Salvi. http://www.vatican.va/content/benedictxvi/es/encyclicals/documents/hf_ben-xvi_enc_20071130_spe-salvi.html.

Congregación para la doctrina de la fe (CDF). (2020). Samaritanus Bonus. https://press.vatican.va/content/salastampa/es/bollettino/pubblico/2020/09/22/carta.html

Domínguez Prieto, X. M. (2017). El arte de acompañar. Madrid: PPC.

Forte, B. (2020). La fe en el Dios de Jesucristo y la pandemia. En W. Kasper, G. Augustin (eds.), Dios en la pandemia (pp. 35-50). Maliaño: Sal Terrae.

Francisco.

Evangelii

Gaudium.

http://www.vatican.va/content/francesco/es/apost_exhortations/documents/papa-

francesco_esortazione-ap_20131124_evangelii-gaudium.html

Gallegos, M.; Zalaquett C.; Luna S. E.; Mazo-Zea R.; Ortiz B. y otros. (2020). Como afrontar la pandemia del coronavirus (COVID-19) en las Américas: recomendaciones y líneas de acción sobre salud mental. Revista interamericana de psicología 54 (01), 1-28. URL: http://hdl.handle.net/2133/18298

Juan Pablo II. (2001). Novo Millenio Ineunte. http://www.vatican.va/content/john-paulii/es/apost_letters/2001/documents/hf_jp-ii_apl_20010106_novo-millennio-ineunte.html.

McIntyre, L. (2018). Posverdad. Madrid: Cátedra.

Moreno, I., S.J. (2020). La pandemia una oportunidad apostólica y espiritual. Revista Aurora (1), 29-31.

Organización Internacional del Trabajo (OIT). (2020). 34 millones de empleos se perdieron por la crisis de América Latina y el Caribe $(01$ de octubre). https://www.ilo.org/global/about-theilo/newsroom/news/WCMS_756778/lang--es/index.htm.

RAE. (2001). Acompañar. Madrid: Espasa Calpe.

Schockel, L. A. (2016). La biblia de nuestro pueblo. Bilbao: Ediciones Mensajero.

Torres, D. (2006). Los ritos funerarios como estrategias simbólicas que regulan las relaciones entre las personas y las culturas, Sapiens 7 (2), 107 - 118.

Trigo, P., S.J. (2020). Desafíos que nos plantea la pandemia, Revista Aurora (1), 15-17.

Valero, C.; Vélez M. F.; Durán, A. A.; Torres, M. (2020). Afrontamiento del COVID-19: estrés, miedo, ansiedad y depresión?, Enfermería Investiga, Investigación, Vinculación, Docencia y Gestión 5 (3), 64-65. DOI: http://dx.doi.org/10.31164/enf.inv.v5i3.913.2020

Yoffe, L. (2014). "Rituales funerarios y de duelos colectivos y privados, religiosos o laicos”, Unifé 22 (2): 145 - 163. DOI: https://doi.org/10.33539/avpsicol.2014.v22n2.182. 